\title{
ANATOMÍA Y MORFOGÉNESIS DE LAS AGALLAS PRODUCIDAS POR LEPTOCYBE INVASA EN PLANTAS DE EUCALYPTUS
}

\author{
ANA M. GONZALEZ¹ y STELLA M. SOLÍS ${ }^{1,2}$
}

\begin{abstract}
Summary: Anatomy and morphogenesis of galls produced by Leptocybe invasa in plants of Eucalyptus. Leptocybe invasa is a gall-inducing wasp that oviposits in the young eucalyptus leaves. The plant responds by forming a gall. As a result, this not only causes rolling leaves and defoliation, but also collapses the tree buds which affect seriously the eucalyptus production. In this paper, it is analyzed the morphogenetic and anatomical changes that are caused by the development of galls and then it is compared with healthy plants. The Eucalyptus grandis and Eucalyptus camaldulensis are cultivated in Corrientes, Argentina, and have been studied with traditional techniques of optical and scanning electron microscopy. The wasp oviposits among the vascular bundles, and the plant produces an hyperplastic tissue that are differed into four layers: nutrient, tanniniferous, sclerotic, and crystalliferous. The circulation of the vascular tissues is obstructed and consequently it is interrupted the normal flow of water and solutes that are transported in the xylem. Hence, this situation produces circular vessel. In fact, it is not only analyzed the morphological and anatomical changes but also the insect development, and this cycle is divided into three stages. This work demonstrates that the formation of galls in the eucalyptus are an excellent example of extended phenotype, where the action of L.invasa induces the abnormal growth of plant tissues because of the increase the number of cells, the collapse of the vascular system of the affected area and the apparition of new anatomical features.
\end{abstract}

Key words: Wasps, crystals, extended phenotype, hyperplasia, Myrtaceae, morphogenesis.

Resumen: Leptocybe invasa o "avispa de la agalla del eucalipto", es un microhimenóptero gallícola que ovipone en hojas jóvenes de eucaliptos. La planta responde formando agallas, que causan enrollamiento, defoliación y colapso de brotes, afectando seriamente la producción. En este trabajo se analizan los cambios morfogenéticos y anatómicos provocados por el desarrollo de las agallas, comparándolos con plantas sanas. Con técnicas tradicionales de microscopía óptica y electrónica de barrido se estudiaron ejemplares de Eucalyptus grandis y E. camaldulensis, cultivados en Corrientes, Argentina. La avispa ovipone entre los haces vasculares, el vegetal produce un tejido hiperplásico que se diferencia en cuatro estratos: nutricio, esclerosado, tanífero y cristalífero. El recorrido de los tejidos vasculares se obstruye, produciéndose "bucles xilemáticos" que interrumpen el flujo normal de agua y fotosintatos. Analizando los cambios morfológicos y anatómicos, junto al desarrollo del insecto, se divide el ciclo en tres etapas. Este trabajo demuestra que la formación de agallas en Eucalyptus representa un excelente ejemplo de fenotipo extendido, donde la acción de $L$. invasa induce al crecimiento anormal de los tejidos vegetales, tanto en aumento del número de células, colapso del sistema vascular de la zona afectada y aparición de nuevas características anatómicas.

Palabras clave: Agallas, avispas, cristales, fenotipo extendido, hiperplasia, Myrtaceae, morfogénesis.

1 Instituto de Botánica del Nordeste, IBONE (UNNE-CONICET), Facultad de Ciencias Agrarias, Argentina, E-mail: anitama39@gmail.com.

${ }^{2}$ Facultad de Ciencias Exactas, Naturales y Agrimensura UNNE, E-mail: stellasolis10@gmail.com. 


\section{INTRODUCCIÓN}

Las agallas son estructuras anormales de parte de los tejidos u órganos de las plantas, que se desarrollan por la reacción específica a la presencia o actividad de un organismo inductor, que puede tratarse de otra planta o un animal, siendo las más frecuentes las producidas por insectos (Meyer, 1987; Shorthouse \& Rohfritsch, 1992).

Las especies del género Eucalyptus (Myrtaceae) son originarias de Australia, aunque han sido plantadas en diversas partes de todos los continentes debido a su interés comercial. En Argentina, hay más de 231.000 hectáreas forestadas con eucaliptos, de las cuales, más del $60 \%$ de las plantaciones son de E. grandis W. Hill y E. camaldulensis Dehnh. y se encuentran en la Mesopotamia, en particular en las provincias de Corrientes y Entre Ríos. Su madera tiene múltiples destinos: principalmente en la elaboración de tableros y pastas celulósicas, $\mathrm{y}$ en menor medida postes, puntales, varillas para alambrados y construcciones rurales (Beale \& Ortiz, 2013).

Leptocybe invasa Fisher \& La Salle (Hymenoptera: Eulophidae: Tetrastichinae) o "avispa de la agalla del eucalipto", es un microhimenóptero gallícola encontrado por primera vez en 2000 en la región del Mediterráneo y Oriente Medio (Mendel et al., 2004). Para el año 2010 invadió los cultivos de eucaliptos de la provincia de Buenos Aires, Argentina (Botto, 2010; Aquino et al., 2011; Bouvet, 2011). El Ministerio de Agricultura, Ganadería y Pesca de Argentina, a través del Servicio Nacional de Sanidad y Calidad Agroalimentaria, fija por Resolución 180/2012 como área controlada de L. invasa a las Provincias de Buenos Aires, Santa Fe, Entre Ríos, Corrientes y La Pampa. En Abril de 2014 por Resolución 166/2014 se declara a L. invasa como plaga no cuarentenaria, manteniendo la emergencia fitosanitaria exclusivamente en los establecimientos productores de material de propagación de Eucalyptus spp. en todo el Territorio Nacional, instruyendo en el control o destrucción del material vegetal infectado.

Esta avispa ovipone en hojas jóvenes, tanto en la zona de la vena media como en pecíolos de hojas y tallos en desarrollo. La planta responde formando una agalla sobre los huevos y larvas, lo que causa alteración en la actividad metabólica en las hojas de la planta, afectando seriamente a la producción de eucaliptos (Botto, 2010; Bouvet, 2011).

El ciclo biológico de L. invasa ha sido ampliamente estudiado (Mendel et al., 2004; Dittrich-Schröder et al., 2014). También se analizó la susceptibilidad de las especies de eucaliptos al ataque de esta avispa (Durand et al., 2011).

Sin embargo, a pesar que la bibliografía existente sobre agallas producidas por insectos es muy amplia, no existen datos referidos a los cambios morfológicos ni anatómicos de las agallas provocadas por L. invasa en especies de eucaliptos. La aparición de agallas en árboles de la provincia de Corrientes motivó el inicio de los estudios morfo-anatómicos a fin de identificar y describir los cambios estructurales y morfogenéticos provocados en la anatomía del árbol.

\section{Materiales y Métodos}

Para este trabajo se procesaron tallos y hojas en distintos grados de desarrollo de dos especies de eucaliptos, con y sin agallas inducidas por $L$. invasa. Las especies analizadas fueron:

Eucalyptus grandis W. Hill. ARGENTINA. Prov. Corrientes: Dpto. Capital, cultivada en plazas de la ciudad, ejemplar infectado por agallas de $L$. invasa, Gonzalez 493, 10-VIII-2014 y ejemplar sano, Gonzalez 494, 10-VIII-2014.

Eucalyptus camaldulensis Dehnh. ARGENTINA. Prov. Corrientes: Dpto. Santo Tomé. Plantas de cultivos comerciales infectadas por agallas de $L$. invasa, Gonzalez 495, 10-VIII-2014.

Los ejemplares testigo fueron depositados en el Herbario del Instituto de Botánica del Nordeste, CTES.

El material vegetal fue fijado en FAA (alcohol $70^{\circ}$, ac. acético y formol, 90:5:5). Para el análisis anatómico se confeccionaron preparados histológicos permanentes incluyendo el material en parafina (Johansen, 1940; Gonzalez \& Cristóbal, 1997). Se realizaron cortes seriados con micrótomo rotativo, de $12 \mu \mathrm{m}$ de espesor y se empleó doble coloración Safranina- fast green (Ruzin, 1999).

La identificación de taninos se realizó con cloruro férrico y carbonato de Sodio (Johansen, 1940). Para la identificación de los cristales se utilizó la técnica de Pizzolato (Silver \& Price, 1969): cortes realizados con micrótomo fueron 
desparafinados y rehidratados, las secciones fueron tratadas con $\mathrm{AgNO}_{3} 5 \%$ y $\mathrm{H}_{2} \mathrm{O}_{2} 30 \%$ (1:1), bajo luz intensa $(60 \mathrm{~W})$; esta técnica se modificó con la posterior tinción con safranina- fast green.

Las observaciones y fotografías fueron realizadas con microscopio Leica DM LB2 equipado con cámara fotográfica y accesorio para análisis con luz polarizada.

Para el análisis con microscopio electrónico de barrido (MEB) se utilizó material fijado en FAA, secado a punto crítico y metalizado con Oro-Paladio. Se utilizó MEB Jeol LV 5800 del Servicio de Microscopía Electrónica de la UNNE, Corrientes.

\section{Resultados}

\section{Morfología de las agallas}

Las agallas se encuentran en las hojas, sobre la lámina foliar están localizadas sobre la vena media, predominantemente en el hipofilo (Figs. 1 A; 2 A); también se encuentran a lo largo de pecíolo, base foliar y tallos jóvenes (Figs. 1 B, C; 2 D). Los ejemplares observados muestran diferentes grados de infección, manifestados por la formación de agallas de varios tamaños. Esta reacción de la planta en presencia de la avispa provoca enrollamiento de hojas, defoliación y colapso de brotes a medida que progresa.

La forma de las agallas es muy variable, ya que puede contener varias cámaras con insectos en su interior (pluriloculares) (Fig. 1 F, J). El tamaño de las agallas puede alcanzar $0,5 \mathrm{~cm}$ de espesor en las venas (Figs. 1 A; 2 A). En la base foliar puede alcanzar 1,6 cm de diámetro (Figs. 1 B-C; 2 D). Como normalmente las agallas formadas por varios insectos confluyen en una sola, su largo total es muy variable, inclusive puede extenderse por varios nudos (Fig. $1 \mathrm{~F}$ ).

El sitio de oviposición se aprecia en los márgenes de la vena media de la lámina, predominantemente en la cara abaxial. El lugar penetrado por el aparato ovipositor de la avispa se observa exteriormente por la aparición de una pequeña costra blanquecina, que permanece durante bastante tiempo mientras se desarrolla la agalla (Figs. 1 D, G; 2 A).

La formación de la agalla comienza a observarse después de la oviposición y responde a los diferentes estadios de desarrollo de L. invasa, desde el huevo, pasando por varios estados larvales hasta alcanzar el estado adulto, momento en el que emerge de la agalla (Fig. $1 \mathrm{I}, \mathrm{J}$ ).

Durante el crecimiento de la larva, se produce un incremento del volumen y extensión de la agalla, tomando el aspecto de una vesícula inflada (Fig. 1 E). Durante los sucesivos estados larvales, exteriormente la agalla puede adquirir tonalidades rojizas, a pesar de que esta característica no es constante en un mismo árbol; se observaron brotes infectados en que cada agalla adquiere tonalidades rojizas solo de un lado (Fig. 1 A-C). A medida que se desarrollan las larvas, agallas cercanas convergen formando masas únicas, por lo que la vesícula adquiere mayor volumen (Fig. 1 F, G).

En la fase final del desarrollo de la avispa, la superficie de la agalla es de color verde-amarillento, con varios orificios de 0,3-0,6 mm de diámetro. Los mismos se originan cuando emergen los adultos (Fig. $1 \mathrm{H}-\mathrm{J}$ ).

\section{Estructura anatómica}

En una hoja sana, la región de la nervadura central presenta epidermis adaxial y abaxial uniestratificadas, cubiertas por una cutícula gruesa. En posición subepidérmica posee colénquima en ambas caras. Se observa la presencia de células taníferas y algunas cavidades secretoras en las cercanías de la epidermis (Figs. 2 H; 3 A).

La provisión vascular de la vena media está formada por un haz colateral, que en hojas pequeñas presenta forma de arco amplio y en hojas de mayor tamaño puede tener además varios haces pequeños, invertidos, ubicados hacia la cara adaxial de la lámina (Figs. 2 C; 3 A). Algunas capas de células parenquimáticas sin cloroplastos rodean el haz vascular, también hay fibras perifloemáticas, escasas y aisladas. La hoja posee mesófilo formado por parénquima clorofiliano en empalizada que ocupa todo el espesor de la lámina; en cercanías de las vena media unas capas de parénquima clorofiliano lagunoso se disponen en el sector medio, constituyendo un mesófilo isobilateral. A nivel de la vena media el parénquima clorofiliano está interrumpido.

El pecíolo presenta epidermis uniestratificada, parénquima clorofiliano escaso, córtex poco desarrollado, con cavidades secretoras; el tejido vascular forma una sifonoestela ectofloica (Fig. 2 F). 

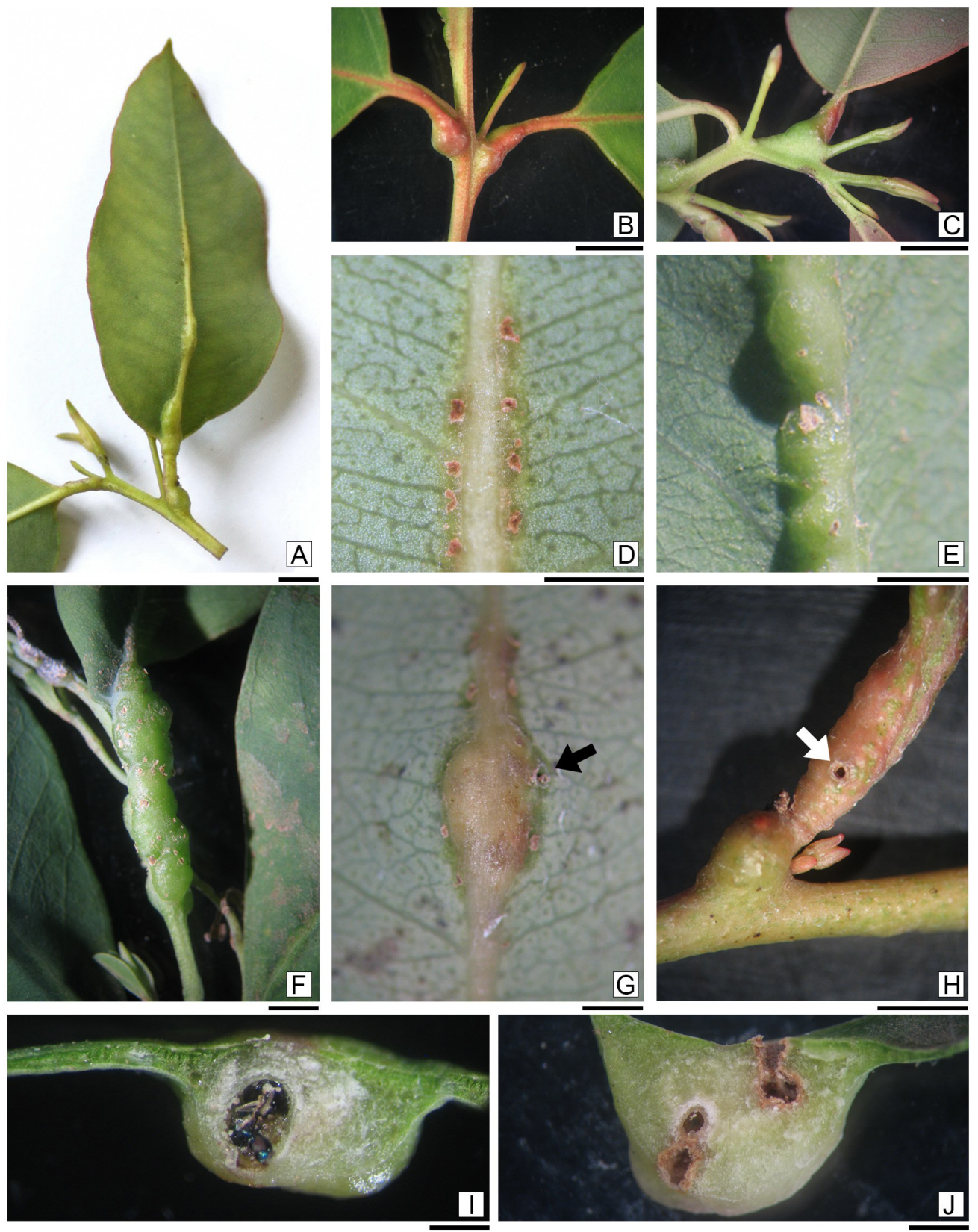

Fig. 1. Eucalyptus grandis. A: Brote mostrando agallas sobre vena media en el hipofilo, pecíolo y base foliar. B: Detalle de agallas en base foliar de dos hojas. C: Brotes con agallas. D-H: Diferentes estadios en el desarrollo de agallas en brotes nuevos. D: Inicio de la agalla, se observan los sitios de ovoposición a ambos lados de la vena media, hipofilo. E: Formación de agallas, se aprecian varias vesículas contiguas sobre la vena media. F: Agalla formada por varias vesículas adyacentes sobre un tallo joven. G: Fase final de formación de una agalla sobre vena media con orificio de salida del insecto (flecha). H: Fase final de una agalla sobre pecíolo donde se observa el orificio de emergencia del insecto (flecha). I-J: Corte transversal de hoja por vena media. I: Cámara larval con adulto consumiendo tejidos para emerger. J: Dos cámaras larvales con canales de emergencia del insecto, uno hacia la cara adaxial y el otro hacia la cara abaxial. Escalas: A-C, $\mathbf{F}, \mathbf{H}=0,5 \mathrm{~cm} ; \mathbf{D}, \mathbf{G}, \mathbf{I}, \mathbf{J}=1 \mathrm{~mm} ; \mathbf{E}=0,5 \mathrm{~mm}$. 

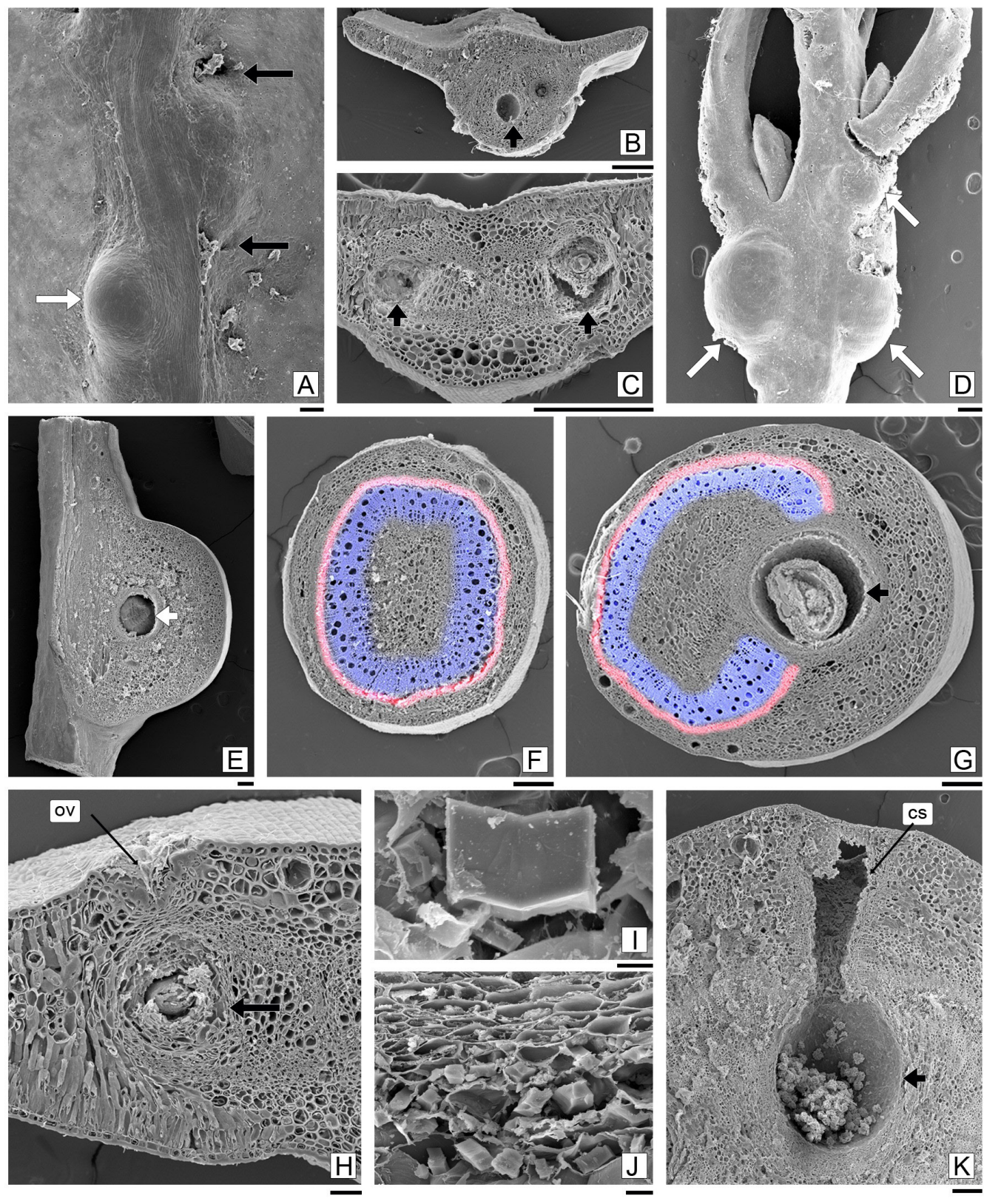

Fig. 2. Eucalyptus camaldulensis. Fotomicrografías con MEB. A: Agallas desarrolladas sobre vena media (flecha blanca), con orificios de oviposición (flechas negras). B: Corte transversal de la vena media donde se observa una cámara larval poco desarrollada (flecha). C: Detalle de vena media, donde se aprecia un haz vascular y dos cámaras larvales (flechas). D: Brote con agallas en diferentes estadios (flechas). E: Corte longitudinal de pecíolo con hiperplasia, formando una protuberancia esférica alrededor de la cámara larval (flecha). F: Corte transversal de pecíolo de una zona inferior a la agalla, se observa el tejido vascular formando una sifonoestela ectofloica. G: Corte transversal de pecíolo a nivel de la agalla, mostrando la cámara larval (flecha) y la interrupción del tejido vascular. H: Inicio de la agalla en vena media, con canal de ovoposición (ov) y cámara larval (flecha). I: Detalle de un cristal prismático. J: Detalle de estratos tanífero y cristalífero. K: Corte de agalla donde se aprecia cámara larval (flecha) con residuos dejados por el insecto y canal de salida (cs). Escalas: A-G, K=200 $\mu \mathrm{m} ; \mathbf{H}-\mathbf{I}=50 \mu \mathrm{m} ; \mathbf{J}=10 \mu \mathrm{m}$. 
El insecto deposita los huevos en la zona del pecíolo o vena media, provocando una pequeña punción que atraviesa la epidermis, tejidos subepidérmicos y llega al haz vascular. El canal formado se tapona con células necrosadas; en la zona epidérmica y tejido subepidérmico dañados se produce una ligera suberificación. Parte del tejido afectado protruye al exterior de la hoja (Figs. $2 \mathrm{H} ; 3 \mathrm{~B}, \mathrm{C}$ ). Por la profundidad en que se realiza la oviposición, los huevos son depositados en los tejidos vasculares del pecíolo o los hacecillos de la vena media.

La formación de la agalla comienza alrededor del huevo depositado, la primera reacción anatómica se observa en las células del parénquima asociado a los tejidos vasculares (tanto xilemático como floemático), que sufren una serie de divisiones mitóticas, asilando y delimitando la cámara donde se completarán todos los estadios del insecto (Figs. $2 \mathrm{~B}, \mathrm{C} ; 3 \mathrm{E}$ ). Las divisiones celulares se producen en el plano tangencial a la superficie interna libre de la cámara. Las células derivadas vuelven a dividirse en varios planos aumentando el volumen de tejido alrededor de la cámara. Esta hiperplasia provoca una protuberancia esférica alrededor del huevo, que se aprecia exteriormente como "agalla" (Fig. 2 A, E, G). La cavidad conteniendo el huevo posee un diámetro de 97,1 (105) 116,2 $\mu \mathrm{m}$.

En el pecíolo, además de la hiperplasia alrededor del huevo depositado, el parénquima fundamental del córtex también muestra divisiones mitóticas, que contribuyen al aumento de volumen de la zona afectada; no se producen modificaciones citológicas notables en las células derivadas (Fig. 2 G).

Mientras se desarrolla la larva en el interior de la cámara, el tejido hiperplásico que la rodea continúa con su actividad meristemática y se diferencia en cuatro estratos: a) nutricio, que limita la cámara larval, b) esclerificado, c) tanífero y d) cristalífero, en contacto con los tejidos vasculares (Fig. 3 F, G).

El estrato nutricio es el más interno, es el conjunto de capas que mantiene su actividad meristemática, produciendo nuevas células hacia el interior de la cámara larval. Sus células mantienen las paredes celulósicas delgadas, citoplasma denso y núcleo conspicuo, no acumulan taninos (Fig. 3 F). Este estrato es consumido por la larva durante su crecimiento (Fig. $3 \mathrm{G}$ ).

El epitelio esclerificado está formado por 3-6 capas de espesor, las células se diferencian en macroesclereidas, tangencialmente alargadas.
Durante la diferenciación las células depositan paredes secundarias lignificadas con numerosas puntuaciones simples, el lumen se llena de compuestos tánicos (Fig. $3 \mathrm{G}, \mathrm{H}$ ).

El tercer estrato, de 3-6 células de espesor, se caracteriza por presentar células de paredes delgadas que se aplastan tangencialmente y acumulan sustancias tánicas (Figs. 2 J; 3 G).

En el estrato externo cada célula mantiene paredes celulósicas delgadas pero se forman 1-3 cristales en cada una, los mismos presentan reacción positiva para oxalato de Calcio al ser teñidos con $\mathrm{AgNO}_{3}$ y $\mathrm{H}_{2} \mathrm{O}_{2}$ (Fig. 3 D, K). Estos cristales son prismas alargados, de sección cuadrangular a pentagonal, con una marca notable en la zona media (Figs. 2 I-J; 3 I-J).

Tanto en la vena media de la hoja como en el pecíolo, el sistema vascular se caracteriza por la presencia de un incipiente cambium que forma xilema secundario, con filas radialmente ordenadas de miembros de vasos que alternan con células parenquimáticas de contenido oscuro. La presencia del L. invasa y formación de la agalla interrumpen el recorrido de estos tejidos vasculares (Fig. 3 D). Los elementos conductores más cercanos al estrato cristalífero se deforman, cambian su recorrido formando "bucles xilemáticos", donde los miembros de vasos y las células parenquimáticas asociadas se disponen helicoidalmente (Fig. 3 L, M). No se forman nuevos elementos conductores que penetren a la agalla.

Durante el desarrollo de L. invasa, las larvas consumen únicamente el estrato nutricio. En ninguna agalla se observó que las restantes capas fueran utilizadas como alimento, tampoco aparecen restos de esclereidas o cristales en el interior de la larva, cuya anatomía se observa en los cortes seriados (Fig. 3 D).

La cámara larval llega a medir 385-(401,2)423,6 $\mu \mathrm{m}$ de diámetro al momento de la emergencia del adulto (Figs. $1 \mathrm{I}-\mathrm{J}$ ).

Cuando se completa el ciclo biológico de $L$. invasa, el adulto emerge consumiendo los tejidos y se forma el canal de salida (Fig. $2 \mathrm{~K}$ ). La cámara larval queda limitada por el epitelio esclerosado, solo quedan remanentes del tejido nutricio (Fig. $3 \mathrm{~N}$ ). Los tejidos que rodean dicho canal sufren numerosas divisiones mitóticas formando un estrato de 8-12 capas de espesor, las células se disponen en filas ordenadas constituyendo un tejido cicatrizal (Fig. $2 \mathrm{~K}$ ). 

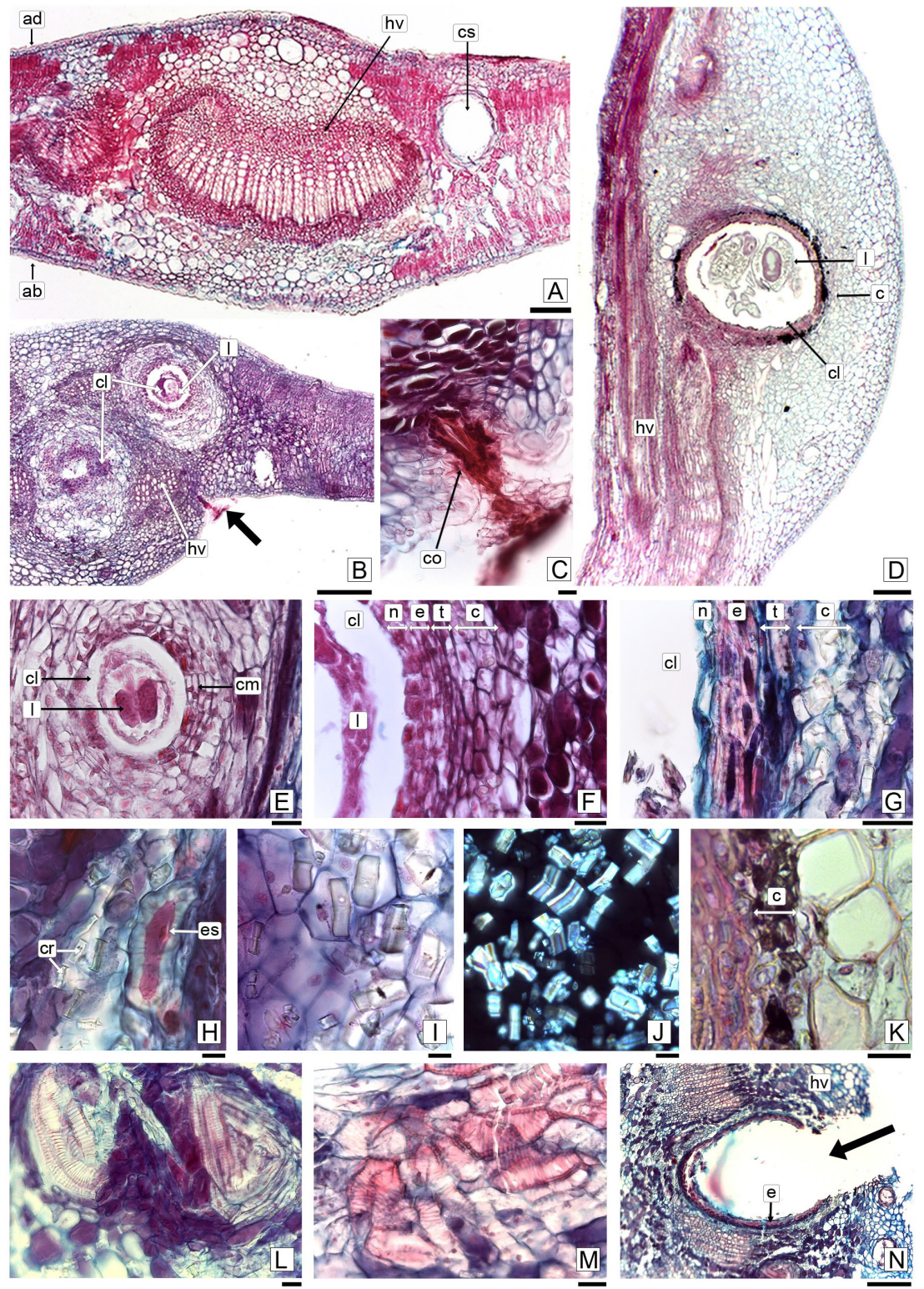

Fig. 3. Eucalyptus grandis. A: Corte transversal de vena media en una hoja sana. B: Corte transversal de vena media en una hoja afectada, donde se observa la formación de dos agallas y la zona del canal de ovoposición (flecha). C: detalle del canal de ovoposición (co) y tejido necrótico en el sitio de la puesta. D: Corte longitudinal de una hoja afectada, donde se observa una agalla (tratada con $\mathrm{AgNO}_{3} \mathrm{y}_{2} \mathrm{O}_{2}$ ). E: Estado inicial de formación de la agalla, la cámara larval se encuentra rodeada por células meristemáticas en división (cm). F y G: Formación de la agalla, se diferencian cuatro estratos: epitelio nutricio (n), estrato esclerificado (e), estrato tanífero colapsado (t) y estrato cristalífero (c). $\mathbf{H}$ : Detalle de cristales (cr) y una macroesclereida (es). I: Estrato cristalífero con cristales prismáticos alargados. J: Cristales con luz polarizada. K: Estrato con cristales de oxalato de calcio, prueba con $\mathrm{AgNO}_{3} \mathrm{y}_{2} \mathrm{O}_{2}$. L: Bucles xilemáticos. M: Detalle de la pared secundaria de vasos y parénquima que forman los bucles xilemáticos. $\mathbf{N}$ : Corte longitudinal de la cámara larval y canal de salida (flecha). Referencias: cara abaxial (ab), cara adaxial (ad), canal secretor (cs), cámara larval (cl), haz vascular (hv), larva (I). Escalas: $\mathbf{A}=0,1 \mathrm{~mm} ; \mathbf{B}, \mathbf{D}, \mathbf{N}=0,2 \mathrm{~mm} ; \mathbf{C}$, F, G, L, K=20 $\mu \mathrm{m} ; \mathbf{H}, \mathbf{I}, \mathbf{J}=10 \mu \mathrm{m}$. 


\section{Discusión y Conclusiones}

Las agallas constituyen un ejemplo de morfogénesis inducida por la presencia de huevos y larvas de insectos (Sinnott, 1960; Shorthouse et al., 2005) y constituyen lo que se denomina fenotipo extendido, a pesar de estar compuestas enteramente de tejidos vegetales del hospedante, su desarrollo está mayoritariamente controlado por los genes del insecto que controlan el crecimiento y la fisiología del órgano atacado para crear un ambiente propicio para el desarrollo larval (Stone \& Schönrogge, 2003; Raman, 2011).

Diversos autores coinciden en el hecho que las agallas tienen su propia morfología y anatomía, como cualquier órgano vegetal (Shorthouse et al., 2005). Mendel et al. (2004) describieron cinco fases en el desarrollo de las agallas de $E$. camaldulensis, basándose exclusivamente en el análisis exomorfológico, considerando la forma y coloración externa de las mismas en relación al ciclo biológico de L. invasa. En el primer estadio las agallas están aisladas, tienen forma esférica y color verde brillante. En el segundo estadio alcanzan su máximo diámetro $(2.7 \pm 0.5 \mathrm{~mm})$. En el estado tres cambia el color a rosa, mantiene el brillo. En fase cuatro la agalla pierde el brillo y se tornan de color rojizo, claro en hojas y oscuro en tallo. La última fase se reconoce por los orificios producidos en la emergencia de la avispa.

En las observaciones realizadas en el presente estudio, combinando datos morfológicos y anatómicos de la agalla con las fases del insecto, se comprobó que los estados tres y cuatro descriptos por Mendel et al. (2004) no están siempre presentes, y se reconocen claramente tres estadios:

Estadio 1: Inicio de la agalla, inducida por la ovoposición y visible exteriormente a través de la formación de tejido necrótico en el sitio de puesta.

Estadio 2: Formación de la agalla, el insecto desarrolla sus estados larvales. Externamente se reconoce por la formación de la agalla de color verde, que puede o no cambiar a tonos rojizos. Anatómicamente en este estadio se produce una hiperplasia del parénquima asociado a los tejidos vasculares, que rodea el huevo de L. invasa. El tejido hiperplásico se diferencia en cuatro estratos: epitelio nutricio, estrato esclerificado, seguido de un estrato tanífero colapsado y finalmente, un estrato cristalífero. No hay hipertrofia de tejidos.
El desarrollo de la agalla interrumpe y afecta el transporte de sustancias por xilema y floema. Una agalla al final de este estadio puede contener varias cámaras larvales, por unión de agallas adyacentes, por lo que su tamaño es variable.

Estadio 3: emergencia del adulto, por el consumo de tejidos desde la cámara hacia alguna epidermis. El vegetal forma tejido cicatrizal alrededor del canal de salida. Exteriormente este estadio se reconoce por el orifico dejado por el insecto.

Una de las características usadas por Mendel et al. (2004) para establecer estadios de agallas en eucaliptos fue la aparición de coloración rojiza superficial. Los antocianos son de aparición frecuente en lesiones en vegetales, entre las que se mencionan las producidas por agallas, siendo en muchas especies un carácter fenotípico de la agalla en sí (Raman, 2011). Para Wool (2004), la pigmentación de las agallas tiene relación positiva con el aumento de la luminosidad y tendría un rol protectivo contra el exceso de luz y por lo tanto su presencia dependerá de las condiciones ambientales y no del agente productor de las agallas. En este estudio de las agallas de Eucalyptus/L. invasa, existe variabilidad en la presencia y localización de la pigmentación, por lo que se sugiere eliminar la coloración como índice de la madurez de la misma; desaconsejando su uso como carácter necesario para definir los estadios, tal como fuera propuesto por Mendel et al. (2004).

Desde los primeros trabajos que estudiaron el tema, se describe la asociación entre Eucalyptus/L. invasa como negativa para el árbol, ya que provoca cambios morfológicos que generan retraso en el crecimiento de los árboles, que pueden morir si se encuentran en fases juveniles (Aquino et al., 2011). A nivel anatómico se puede comprender por qué ocurren estos fenómenos. El huevo es depositado a nivel del tejido vascular, por lo que durante los sucesivos estadios larvales el desarrollo de la agalla disminuye la superficie ocupada por xilema principalmente, de este modo el suministro de agua y solutos a las hojas queda interrumpido.

La formación y diferenciación de los elementos conductores está influenciada por el flujo polar de auxinas y citocininas (Aloni, 2013). Esta interrupción de los haces vasculares por $L$. invasa provoca la formación de "bucles xilemáticos", zonas donde los vasos y el parénquima xilemático asociado presentan un recorrido circular formando 
remolinos y anillos cerrados de diferentes tamaños. Estas estructuras, descriptas inicialmente e interpretadas como vasos circulares por Vochting (1918), son poco usuales en plantas intactas, pero comunes en la parte basal o raíz de los tejidos cercanos a las heridas transversales o en la porción superior de una ramificación (Sachs \& Cohen, 1982). Estos vasos circulares no funcionan en el transporte de agua y su presencia interrumpe el flujo xilemático hacia la parte apical del órgano, cambiando la polaridad en el transporte de las auxinas (Sachs, 1981 a, b, 2005). Los bucles xilemáticos ya fueron observados en otros tejidos, por ejemplo en callos (Sachs \& Cohen, 1982); en segmentos nodales cultivados in vitro (Kurczyriska, \& Hejnowicz, 1991); en agallas formadas por Agrobacterium (Schurr et al., 1996) y en raíces leñosas afectadas por plantas holoparásitas, como es el caso del leño de la raíz de Piptadenia rigida invadida por Lophophytum leandri (Gonzalez \& Mauseth, 2010).

Una de las agallas mejor descriptas, especialmente en su morfogénesis, es la producida por cinípidos (Hymenoptera, Cynipidae) que atacan especies de Quercus y Rosa (Rohfritsch, 1992; Harper et al., 2004). Durante su desarrollo se destaca la producción de un tejido nutricio y un estrato esclerosado. El tejido donde se deposita el huevo reacciona inicialmente con un fenómeno denominado metaplasia por Meyer (1987), siendo inducido a la rediferenciación con la producción inmediata de nuevas células, las mismas rodean a la cámara larval y permanecen con citoplasma denso. Estas características histológicas concuerdan con las observadas en tejidos de agallas de eucaliptos afectados por L. invasa.

En las agallas de las dos especies de Eucaliptus analizadas se observó la presencia de un estrato cristalífero, con cristales de forma muy particular. Los cristales y su morfología ha sido ampliamente documentada en los vegetales (Franceschi \& Horner, 1980), siendo sus formas típicas descriptas como prismas, estiloides, rafidios, drusas o arena cristalina (Webb, 1999). Su presencia y tipología son usados como caracteres taxonómicos en numerosos taxa, reconociendo que su formación está controlada genéticamente (Ilarslan et al., 2001). Su localización, tamaño y forma pueden sin embargo verse afectados por factores como luz, temperatura, y herbivoría según diversos autores
(Kuo-Huang et al., 2007; Meriç, 2009).

La presencia de cristales en Eucaliptus ha sido descripta como parte del metabolismo normal, en leño y corteza en forma de drusas y prismas (Quilhot et al., 1999), también en las hojas se describen monocristales y drusas rodeando a la vena media y en el mesófilo (Santos et al., 2008; Malinowski, 2009). Por otro lado también se destaca la aparición de cristales como fenómeno asociado a la presencia de micorrizas en raíces de eucaliptos (Gonzalez et al., 2009). La presencia del estrato cristalífero en las agallas evidentemente es un producto del fenotipo extendido de L. invasa sobre Eucalyptus, lo cual explicaría la morfología particular del cristal, no descripta previamente en la anatomía de la especie.

Los estratos cristalífero y esclerosado, a pesar de que su presencia es un efecto de fenotipo inducido por $L$. invasa, evidentemente constituyen una barrera por parte del vegetal al área consumida por las larvas, ya que nunca se encuentran disgregados, como tampoco dentro del insecto.

La formación de agallas es un proceso complejo, donde el proceso normal de diferenciación de tejidos en Eucalyptus es afectado por la acción del insecto durante su ciclo biológico. En el caso de las especies en estudio se aprecia la producción de nuevas células y componentes citoplasmáticos, inclusive induce a la formación de cristales de formas completamente nuevas para las especies de Eucalyptus.

\section{Agradecimientos}

A la Ing. Agr. Mabel Mendez del SENASA, por el envío de ejemplares de eucaliptos cultivados infectados por $L$. invasa. Este trabajo fue realizado con el aporte de subsidios de CONICET (PIP 1122011-0100906) y UNNE (PICTO 0199-2011) a la primera autora. Se agradecen las correcciones realizadas por los revisores.

\section{Biblografía}

ALONI, R. 2013. The role of hormones in controlling vascular differentiation. In: FROMM, J. (ed.), Plant cell monographs: cellular aspects of wood formation, pp. 99-140. Springer-Verlag, Berlin Heidelberg. 
AQUINO, D. A., E. N. BOTTO, M. S. LOIÁCONO \& P. PATHAUER. 2011. "Avispa de la agalla del eucalipto", Leptocybe invasa Fischer \& Lasalle (Hymenoptera: Eulophidae: Tetrastichinae), en Argentina. RIA 37: 159-164.

BEALE, I. \& E. C. ORTIZ. 2013. El Sector Forestal Argentino: Eucaliptos. Revista de Divulgación Técnica (REDITA - FCA, UNCa) 53: 1-10.

BOTTO, E. N. 2010. Detección de Hymenóptero formador de agallas en eucaliptos (Hymenoptera: Chalcidoidea, Eulophidae), 99\% de similitud biológica y morfológica con Leptocybe invasa Fisher and LaSalle. Sistema Nacional Argentino de Vigilancia y Monitoreo de Plagas (SINAVIMO). [online]. Disponible en: http://www.sinavimo.gov. $\mathrm{ar} /$ deteccion/4493 [Acceso: octubre 2014].

BOUVET, J. P. R. 2011. Manual de Insectos asociados al cultivo de eucalipto. Ediciones INTA, Bs As.

DITTRICH-SCHRÖDER, G., M. HARNEY, S. NESER, T. JOFFE, S. BUSH, B. P. HURLEY, M. J. WINGFIELD \& B. SLIPPERS. 2014. Biology and host preference of Selitrichodes neseri: A potential biological control agent of the Eucalyptus gall wasp, Leptocybe invasa. Biol. Control 78: 33-41.

DURAND, N., J. C. RODRIGUES, E. MATEUS, C. BOAVIDA \& M. BRANCO. 2011. Susceptibility Variation in Eucalyptus spp. in relation to Leptocybe invasa and Ophelimus maskelli (Hymenoptera: Eulophidae), two invasive gall wasps occurring in Portugal. Silva Lusitana 19: 19-31.

FRANCESCHI, V. R \& H. T. HORNER. 1980. Calcium oxalate crystals in plants. Bot. Rev. 46: 361-427.

GONZALEZ, A. M. \& C. L. CRISTÓBAL. 1997. Anatomía y ontogenia de semillas de Helicteres lhotzkyana (Sterculiaceae). Bonplandia 9: 287-294.

GONZALEZ, A. M. \& J. D. MAUSETH. 2010. Morphogenesis is highly aberrant in the vegetative body of the holoparasite Lophophytum leandri (Balanophoraceae): All typical vegetative organs are absent and many tissues are highly modified. Int. J. Plant Sci. 171: 499-508.

GONZALEZ, J., A. ZAMBRANO, M. DUTRA COSTA, I. RIBEIRO SILVA, J. C. LIMA NEVES, N. F. DE BARROS \& A. CHAER BORGES. 2009. Acúmulo de ácido oxálico e cristais de Cálcio em ectomicorrizas de eucalipto. I - Produção de ácido oxálico e concentração de nutrientes em raízes laterais finas colonizadas por fungos ectomicorrízicos. Rev. Bras. Cienc. Solo 33:541-553.

HARPER, L. J., K. SCHÖNROGGE, K. Y. LIM, P. FRANCIS \& C. P. LICHTENSTEIN. 2004. Cynipid galls: insect-induced modifications of plant development create novel plant organs. Plant Cell Environ. 27: 327-335.
ILARSLAN, H., R. G. PALMER \& H. T. HORNER. 2001. Calcium oxalate crystals in developing seeds of soybean. Ann. Bot. 88: 243-257.

JOHANSEN, D. A. 1940. Plant Microtechnique.Mc Graw Hill Book Co. New York.

KUO-HUANG, L. L., M. S. B. KU \& V. R. FRANCESCHI. 2007. Correlations between calcium oxalate crystals and photosynthetic activities in palisade cells of shade-adapted Peperomia glabella. Bot. Stud. 48: 155-164.

KURCZYRISKA, E. U. \& Z. HEJNOWICZ. 1991. Differentiation of circular vessels in isolated segments of Fraxinus excelsior. Physiol. Plantarum. 83: 275-280.

MALINOWSKI, L. R. L., T. NAKASHIMA \& Y. ALQUINI. 2009. Caracterização morfoanatômica das folhas jovens de Eucalyptus globulus Labill ssp. Bicostata (Maiden et al.) J.B. Kirkpat. (Myrtaceae). Lat. Am. J. Pharm. 28: 756-61.

MENDEL, Z., A. PROTASOV, N. FISHER \& J. LA SALLE. 2004. Taxonomy and biology of Leptocybe invasa gen. \& sp. n. (Hymenoptera: Eulophidae), an invasive gall inducer on Eucalyptus. Aust. J. Entomol. 43: 101-113.

MERIC, Ç. 2009. Calcium oxalate crystals in some species of the Tribe Inuleae (Asteraceae). Acta Biol. Cracov Bot. 51: 105-110.

MEYER, J. 1987. Plant galls and gall inducers. Gebriider Bomtraeger. Berlin, Germany.

QUILHOT, T., H. PEREIRA \& H. G. RICHTER. 1999. Variability of bark structure in plantation-grown Eucalyptus globulus. IAWA Journal 20: 171- 180.

RAMAN, A. 2011. Morphogenesis of insect-induced plant galls: facts and questions. Flora 206: 517-533.

ROHFRITSCH, O. 1992. Patterns in gall development. In: SHORTHOUSE, J. D. \& O. ROHFRITSCH (eds.), Biology of Insect Induced Galls, pp. 60-86. Oxford University Press. New York.

RUZIN, S. E. 1999. Plant microtechnique and microscopy. Oxford University Press. New York.

SACHS, T. 1981a. The control of the patterned differentiation of vascular tissues. Adv. Bot. Res. 9: 151-262.

SACHS, T. 1981b. Polarity changes and tissue organization in plants. In: SCHWEIGER, H. G. (ed.), International Cell Biology 1980-1981, pp. 489-496.Springer-Verlag Berlin, Heidelberg.

SACHS, T. 2005. Pattern formation in plant tissues. Cambridge University Press.

SACHS, T. \& D. COHEN. 1982. Circular vessels and the control of vascular differentiation in plants. Differentiation 21: 22-26.

SANTOS, L. D. T., M. THADEO, L. IAREMA, R. M. S. ALVES MEIRA \& F. A. FERREIRA. 2008. Foliar 


\section{A. M. Gonzalez y S. M. Solís - Anatomía y morfogénesis de las agallas}

anatomy and histochemistry in seven species of Eucalyptus. Arvore 32: 769-779.

SCHURR, U., B. SCHUBERTH, R. ALON, K. S. PRADEL, D. SCHMUNDT BAHNE \& C. I. ULLRICH. 1996. Structural and functional evidence for xylem-mediated water transport and high transpiration in Agrobacterium tumefaciens. Induced tumors of Ricinus communis. Bot. Acta 109: 405411.

SHORTHOUSE, J. D. \& O. ROHFRITSCH. 1992. Biology of insect-induced galls. Oxford University Press. New York.

SHORTHOUSE, J. D., D. WOOL \& A. RAMAN. 2005. Gall-inducing insect: nature's most sophisticated herbivores. Basic. Appl. Ecol. 6: 407-411.

SILVER, V. L. \& J. L. PRICE. 1969. Demonstration of calcium oxalate crystals in plant tissues by Pizzolato $\left(\mathrm{AgNO}_{3}-\mathrm{H}_{2} \mathrm{O}_{2}\right)$ method. Stain Tech. 44: 257-259.

SINNOTT, E. W. 1960. Plant Morphogenesis. McGrawHill, New York.
STONE, G. N \& K. SCHÖNROGGE. 2003. The adaptive significance of insect gall morphology. Trends Ecol. Evol. 18: 512-521.

VÖCHTING, H. 1918. Untersuchungen zur experimentellen Anatomie und Pathologie des Pflanzenkörpers. II Die Polarität der Gewächse. Verlag H. Lauppschen Buchhandlung, Tübingen.

WEBB, M. A. 1999. Cell-mediated crystallization of calcium oxalate in plants. Plant Cell 11:751-761.

WOOL, D. D. 2004. Galling aphids: Specialization, biological complexity, and variation. Annu. Rev. Entomol. 49:175-192.

Recibido el 20 de noviembre de 2014, aceptado el 31 de marzo de 2015 
